\title{
O clássico não sai de moda
}

Resenha da obra:

CALVINO, Ítalo. Por que ler os clássicos. 2.ed. São Paulo: Companhia das Letras, 1993. 280 p.

\section{DOI: $10.47224 /$ rm.v5i10.82}

Leticia Santos Gomes

e-mail: leticiagomes180@hotmail.com

\section{Resumo}

\begin{abstract}
Aprende-se a ser professor em diferentes espaços e tempos. O artigo trata de algumas reflexões construídas acerca de uma experiência de aprendizagem realizada na Docência Orientada, projeto desenvolvido em uma escola pública na cidade de Araguari. A categoria central - aprendizagens para sermos professores nos encaminha para outros movimentos e momentos reflexivos, quando somos convidados a pensar a formação de professores para além dos cursos acadêmicos de formação inicial. Percebemos, então, que o espaço graduação como lócus de formação de um professor. Posto isso, temos uma possibilidade de aprendizagem sobre a docência, na experiência de atuação compartilhada na sala de aula, principalmente, tratando-se de um curso de formação de professores. Algumas considerações podem ser trazidas como possíveis conclusões: a experimentação da Docência Orientada como um tempo/espaço formador tem possibilitado, além da construção de processos de identificação com a docência, a construção de alternativas de ensino na perspectiva da construção de uma pedagogia universitária. Afastando-se da concepção de ensino como dom, como vocação ou "amadorismo", há nas escritas o desejo da construção de um perfil profissional, uma professoralidade que toma como fonte de construção de saberes professores que produziram marcas nas suas trajetórias de formação acadêmica.
\end{abstract}

Palavras-chave: Docência, Formação de Professores, Prática Pedagógica.

\section{Abstract}

One learns to be a teacher in different spaces and times. The article deals with some reflections built on a learning experience carried out in Oriented Teaching, a project developed in a public school in the city of Araguari. The central category - learning to be a teacher leads us to other movements and reflective moments when we are invited to think about teacher education beyond the academic courses of initial training. We perceive, then, that the graduation space as a locus of teacher training; That said, we have a possibility of learning about teaching, in the experience of shared action in the classroom, mainly, as it is a teacher training course. Some considerations can be brought as possible conclusions: the experimentation of Oriented Teaching as a formative time / space has made possible, in addition to the construction of identification processes with teaching, the construction of teaching alternatives in the perspective of the construction of a university pedagogy. Moving away from the concept of teaching as a gift, as a vocation or "amateurism", there is a desire in the writings to build a professional profile, a professorship that takes teachers who produced marks in their academic education trajectories as a source of building knowledge.

Keywords: $\quad$ Teaching, Teacher Training, Pedagogical Practice.

\section{INTRODUÇÃO}

Nascido em Santiago de Las Vegas, cuba, Italo Calvino (1923-1985), foi para a Itália logo após o se nascimento. Tornou-se um dos mais importantes escritores italianos do século XX. Formado em Letras, participou na resistência ao fascismo durante a Segunda Guerra Mundial e foi membro do Partido
Comunista Italiano até 1956, tendo se desfiliado em 1957. A sua carta de renúncia ficou famosa em 1957. Entre as suas principais obras destacam se: A trilha dos ninhos de aranha, 1947. As cidades invisíveis 1972, e Porque Ler Os clássicos. Essa última será objeto de análise a seguir.

Os clássicos fazem parte da nossa formação intelectual uma antologia variada de grandes 
clássicos, obras que marcam uma época e que aceitam ser objeto de dissecação das mais variadas formas de crítica: sociológica, psicológica, psicanalítica, etc. Mas afinal de contas o que são clássicos? E por que se deve lê-los? A obra de Italo Calvino, Por que ler os Clássicos, oferecem algumas respostas a essas constantes perguntas, algumas que geram questionamentos e outras que entrarão no consenso da maioria de seus leitores, mas com certeza todas são proveitosas para o âmbito do conhecimento. Com verdadeiro sentimento ao trabalho, Calvino desvenda as várias possibilidades a respeito do que seja um clássico, para após apresentar com uma leitura dos seus próprios clássicos, obras dos autores que segundo ele são os mais importantes do Ocidente.

No primeiro capítulo o qual se dá fundamento ao título do livro, apresenta-se o questionamento a respeito do que seja clássico e a sua definição. Para qual Calvino aborda quatorze possíveis definições, entre elas "1. Os clássicos são aqueles livros dos quais, em geral, se ouve dizer: 'Estou relendo...' e nunca 'Estou lendo...'.", "2. Dizem-se clássicos aqueles livros que constituem uma riqueza para quem os tenha lido e amado; mas constituem uma riqueza não menor para quem se reserva a sorte de tê-los pela primeira vez nas melhores condições para apreciá-los", "3. Os clássicos são livros que exercem uma influência particular quando se impõem como inesquecíveis e quando se ocultam nas dobras da memória, mimetizando-se como inconsciente coletivo e individua", "4. Toda releitura de um clássico é uma leitura de descoberta como a primeira", "5. Toda primeira leitura de um clássico é na realidade uma releitura" e "6. Um Clássico é um livro que nunca terminou de dizer aquilo que tinha para dizer".

Nesses trechos iniciais usados para definir um clássico, o autor aponta o fato de que as experiências de leitura quando feitas em idade jovem são diferentes das realizadas quando feitas em idade mais madura. Pois, a leitura dos clássicos feita quando jovem pode ser de pouco proveito, de pouca identificação e intensidade, mas, ao mesmo tempo pode vir a ser uma leitura formativa, que fornecerá a ampliação do repertório do leitor. O conteúdo é abstraído e torna-se parte do inconsciente, por isso para autor é sempre importante revisitar as obras mais importantes da juventude, pois mesmo que seja a mesma obra a leitura será sempre feita de maneira diferente, trazendo elementos novos, distintas análises e reflexões a cada leitura. Calvino prioriza a atenção para os clássicos universalmente conhecidos, mas também para aqueles que ainda possuem sua popularidade mais restrita entre os leitores.
Nas definições posteriores Calvino diz: "7. Os clássicos são aqueles livros que chegam até nós trazendo consigo as marcas das leituras que precederam a nossa e atrás de si os traços que deixaram na cultura ou nas culturas que atravessaram (ou mais simplesmente na linguagem ou nos costumes)", "11. O 'seu' clássico é aquele que não pode ser-lhe indiferente e que serve para definir a você próprio em relação e talvez em contraste com ele.", "13. É clássico aquilo que tende a relegar as atualidades à posição de barulho de fundo, mas ao mesmo tempo não pode prescindir desse barulho de fundo." e "14. É clássico aquilo que persiste como rumor mesmo onde predomina a atualidade mais incompatível".

Diante dessas definições o autor levanta a questão que dá título a sua obra de porquê devemos ler os clássicos e esse motivo é o fato de que eles possuem uma enorme bagagem de conhecimento. Na maioria das vezes, os livros apresentam um grande contexto histórico, abordando a moral e o costume da época no qual ele está inserido. Além disso, segundo ele os clássicos são obras bem escritas com riqueza de detalhes, nos quais os autores trabalham de forma clara e objetiva usando as palavras e organizam suas ideias de forma sucinta. Calvino também diz que os clássicos sempre surpreendem e se revelam inesperados. Porém, é preciso haver interesse e curiosidade do leitor, que ao procurar a obra deve ir por vontade própria, e não obrigado.

Segundo a perspectiva do autor, os livros clássicos apresentados através da escola estão ali para serem apenas mostrados ao leitor, cabe a cada um posteriormente fazer uma seleção e decidir o que de verdade gostaria de ler. Calvino diz: o clássico é capaz de te definir, dependendo da relação de identificação criada. Assim se pode criar uma relação com o livro. Se a leitura de um clássico for realizada hoje, com certeza ela trará reflexões e análises a respeito de problemas da atualidade, mesmo ele sendo antigo ou moderno.

No entanto ainda que a leitura dos clássicos seja extremamente importante, o autor alerta que é preciso intercalar com livros da atualidade, para não se perder em uma "nuvem atemporal". Além disso, ao ler-se um clássico não se devem desvalorizar as obras contemporâneas, que também necessitam de serem valorizadas.

Nos capítulos posteriores Calvino traz alguns ensaios esclarecidos em que apresenta alguns clássicos que na sua visão são considerados os melhores, e mostra como esses clássicos conseguiram espaço universal. Ganhará destaque nesse texto os três primeiros ensaios referentes aos clássicos de A Odisseia de 
Homero, intitulado "As Odisseias na Odisseia", "Xenofonte, Anábase" e "Ovídio e a contiguidade universal".

O primeiro clássico apresentado pelo autor, clássico esse de grande renome e um dos primeiros textos épicos produzidos no Ocidente, é mostrado por Calvino como se fosse uma grande Odisseia com várias outras odisseias dentro de si. $\mathrm{O}$ autor discorre a respeito de diversos fatos sobre a epopeia. Segundo ele, uma das novidades da Odisseia foi justamente "ter colocado um herói épico como Ulisses às voltas 'com bruxas e gigantes, monstros e devoradores de homens', isto é, em situações de um tipo de saga mais arcaico, cujas raízes devem ser buscadas 'no mundo da antiga fábula e até de primitivas concepções mágicas e xamanísticas". Dessa maneira, submetendo um herói, tradicionalmente um paradigma de virtudes aristocráticas e militares, às "mais duras fadigas, dor e solidão", Homero o aproxima do homem moderno.

Assim, a persistência de Ulisses para atingir seus objetivos e sua luta contra o universo arcaico representam, em larga medida, o homem moderno em seu embate diário contra as angústias e dores de seu tempo. Lançando mão da sabedoria e do equilíbrio, mas também de astúcia, o herói constrói uma nova ordem que confronta o obscurantismo de um mundo dominado pelos caprichos dos deuses.

A modernidade temática, construída sobre dicotomias - seja entre o mundo mítico e o mundo dos homens, seja entre a necessidade de prosseguir e os obstáculos que incitam à permanência -, encontra consonância com um registro de tipo mais realista. Esse mundo nos é apresentado por meio de uma técnica narrativa largamente empregada na literatura dos tempos modernos, a inversão temporal, segundo a qual os eventos são narrados em retrospectiva, em uma ordem não cronológica. Quanto ao protagonista Ulisses, ele afirma que o mais importante mesmo é que o mesmo não se esqueça de sua casa e de todas as suas coisas deixadas, e, portanto, que não perca o fio condutor que o levará de volta a sua casa e à sua realidade, pois esse será o eixo de sua sobrevivência. Tanto que Penélope tricota de dia e a noite desfia, o que denota inicialmente a necessidade do fio condutor, do eixo que liga os dois planos, o plano central da epopeia (social) com o plano final da odisseia (heroica).

No capítulo posterior, Xenofonte, Anábase, Calvino diz que a impressão mais forte que Xenofonte causa para quem o lê hoje é de estar vendo um velho documentário de guerra, como os que são reapresentados de vez em quando no cinema ou na televisão. O fascínio do preto e branco, do filme meio apagado, com fortes contrastes de sombras e movimentos acelerados [...]. O clássico é considerado pelo autor um épico às avessas, no qual apresenta o movimento epopeico de um grupo de gregos, que em uma missão à Ásia Menor para combater o príncipe Artaxerxes II, são derrotados e sem líderes, mais de dez mil soldados estão no meio das linhas dos povos inimigos, tendo que voltar à sua pátria atravessando cidades de outros povos, levando consigo destruição, mulheres e saqueando.

O detalhamento com que Xenofonte descreve toda a movimentação de guerra, da ausência de generais a líderes emergentes, das estratégias de guerras e reuniões marcadas em atas. Um monstruoso corpo de homens armados, que querem voltar para a casa em meio à neve, deserta e outras civilizações faz de Anábase um clássico de guerra, uma obra prima que deve ser lida por aqueles que gostam do tema e também, principalmente, por aqueles que não gostam, uma vez que rememora a noção plena de união enquanto atributo de sobrevivência física e moral: física, pois todos dependem de todos para manterem-se vivos; e moral, pois a noção de pátria e identidade é montada a partir da conjunção entre eles, da noção de unidade e nação.

Esta ideia de unidade grupal é acentuada quando da reiteração dada ao signo "gafanhotos" exposta por Calvino. Uma nuvem de gafanhotos em busca de um retorno e tentando manter uma integridade helênica dentro do barbarismo externo (outras civilizações) e o barbarismo existente dentro de cada soldado.

Em "Ovídio e a contiguidade universal", Calvino afirma: "As metamorfoses são poemas da rapidez, tudo deve seguir-se em ritmo acelerado, impor-se à imaginação, adquirir evidência, dissolver-se. É o princípio do cinematógrafo: cada verso como cada fotograma deve ser pleno de estímulos visuais em movimento".

Nesse sentido, as transformações do universo clássico, dos objetos, de Aracne em Aranha, depois de desafiar Minerva ao tecer temas das desventuras e orgias dos deuses no Olimpo, ou de Palas incitada por Apolo e Netuno, vão construindo uma narrativa forte, cinematográfica, onde cada cena estará completa de estímulos prontos a explodir diante do leitor. Esta rapidez descritiva e enunciativa mostra a força atual de Ovídio, até mesmo quando descreve o acidente do carro solar, destruído pelo raio de Júpiter. A cena é construída a partir do relato cinético do movimento do carro espatifando-se, até a descrição anatômica dos pedaços de gente expostos na rua, tais 
acontecimentos causa grande impacto nos leitores dessa obra.

O destaque dessa obra é que ela não é algo que só pode ser entendido por estudantes de literatura, mas tem tudo para encantar e auxiliar os leigos que estão justamente nesse ponto em que querem aumentar seus conhecimentos acerca da literatura, mas que ainda estão confusos com a grande quantidade de livros existentes. É importante acompanhar o ponto de vista de Calvino, que passo a passo formula definições, que se evoluem conforme são explicadas. No seu estilo, Calvino aborda um assunto de forma profunda, mas sem que se torne chato como acontece em textos de especialistas. Depois de formulada a resposta para essa pergunta, e concluído que ler clássicos é melhor do que não os ler.

Assim, o livro Por que ler os Clássicos é de escrita simples, objetiva e reflexiva, cheia de perguntas lançadas ao público leitor, fazendo com que haja a reflexão a respeito dos temas abordados. Ele próprio, um clássico segundo sua própria definição, que merece ser lido e relido sem jamais esgotar o seu potencial. Á todos aqueles que se identificam, valorizam e gostam de literatura e querem cada vez mais conhecê-la para abstrair dela o melhor, porque ler os clássicos é essencial.

\section{REFERÊNCIA}

CALVINO, Ítalo. Por que ler os clássicos. 2.ed. São

Paulo: Companhia das Letras, 1993. 280 p. 